\title{
Postnatal depression among Bahraini women: prevalence of symptoms and psychosocial risk factors
}

\author{
F.H. Al Dallal' and I.N. Grant ${ }^{2}$
}

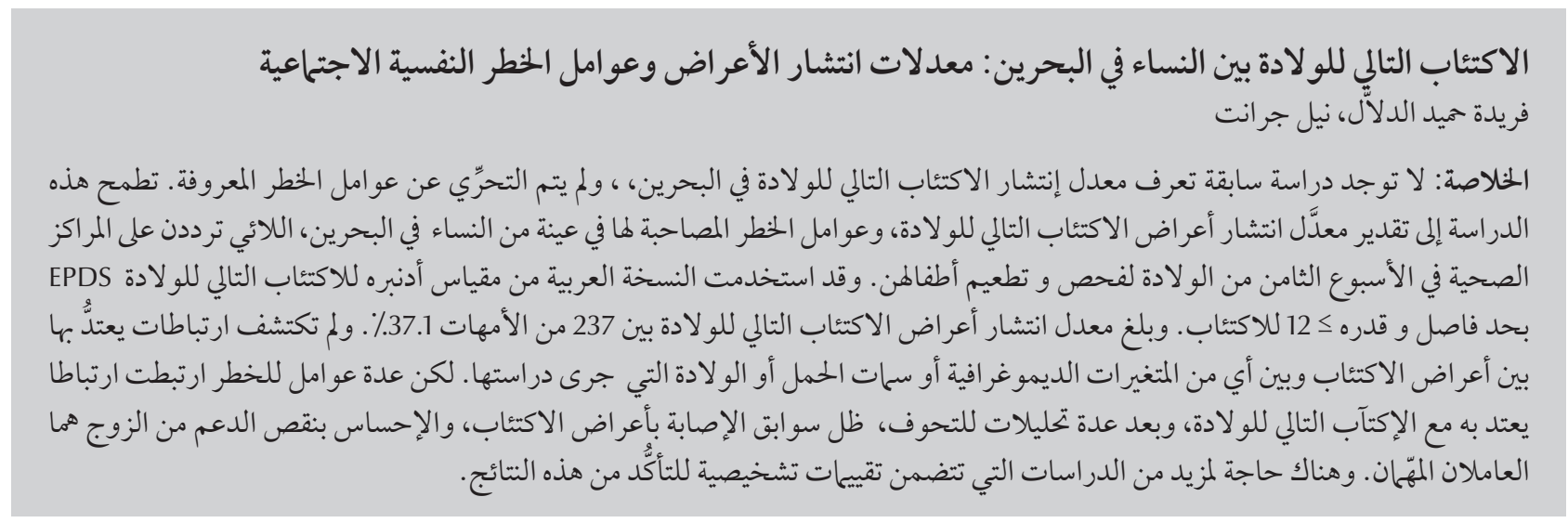

ABSTRACT The prevalence of postnatal depression in Bahrain is unknown and screening for known risk factors does not take place. This study estimated the prevalence of postnatal depressive symptoms and the associated risk factors among a random sample of Bahraini women attending primary health care centres with their babies for the 8-week child check-up. The Arabic version of the Edinburgh Postnatal Depression Scale (EPDS) was used with a cut-off score of $\geq 12$ for depression. The prevalence of postnatal depressive symptoms among 237 mothers was $37.1 \%$. No significant relationships were identified between depression symptoms and any of demographic variables or pregnancy/birth characteristics studied. However, several psychosocial risk factors were significantly associated with postnatal depression and, after multiple regression analysis, a history of depressive symptoms and perceived lack of support from the husband remained significant factors. Further studies that include diagnostic assessments are needed to confirm these findings.

Dépression postnatale chez des femmes bahreïnies : prévalence des symptômes et des facteurs de risque psychosociaux

RÉSUMÉ La prévalence de la dépression postnatale à Bahreïn n'est pas connue et aucun dépistage des facteurs de risque avérés n'est réalisé. La présente étude a estimé la prévalence des symptômes de dépression postnatale et des facteurs de risque associés dans un échantillon aléatoire de femmes bahreïnies consultant les centres de soins de santé primaires avec leur bébé pour la visite des huit semaines. La version en langue arabe de l'Edinburgh Postnatal Depression Scale (Échelle de dépression postnatale d'Édimbourg) a été utilisée avec une valeur seuil supérieure ou égale à 12 pour la dépression. La prévalence des symptômes de la dépression postnatale chez les 237 mères de l'étude était de 37,1 \%. Aucune relation significative n'a été identifiée entre les symptômes de dépression et les variables démographiques ou les caractéristiques des grossesses ou des accouchements étudiés. Toutefois, plusieurs facteurs de risque psychosociaux étaient significativement associés à la dépression postnatale et, après l'analyse de régression multiple, des antécédents de symptômes dépressifs ainsi que le sentiment de recevoir un soutien insuffisant de la part du conjoint se sont révélé être des facteurs importants. Des études supplémentaires comprenant des évaluations diagnostiques sont requises pour confirmer ces résultats.

'Primary Health Care, Ministry of Health, Manama, Bahrain (Correspondence to F.H. Al Dallal: drfareeda@hotmail.co.uk). ${ }^{2}$ Department of Family Medicine, College of Medicine and Medical Sciences, Arabian Gulf University, Manama, Bahrain.

Received: 02/08/10; accepted: 19/12/10 


\section{Introduction}

Postnatal depression is an important health issue, with not only immediate health effects on the woman and her selfconfidence as a mother, but also on her infant's social, emotional, cognitive [1$3]$ and even physical development $[4,5]$. Varying rates of postnatal depression and depressive symptoms have been reported within and across countries. The rate of postnatal depression ranges from $10 \%$ to $15 \%$ in developed countries [6-8], but is higher in developing countries where rates ranging from $16 \%$ to $36 \%$ have been recorded [9-15].

Several risk factors have been found to be associated with postnatal depression, including a mother's history of major depressive disorder and a past history of postnatal depression $[8,10]$, depression during pregnancy $[11]$ and a family history of depression [16]. Other important factors in some low-income countries are family disruption and a lack of social support $[9-14,17]$, poor economic status and dissatisfaction with having a female child $[10,14,17]$. Not breastfeeding, stressful life events, baby's health problems and unintended pregnancy were also found to be associated with postnatal depression $[9-13,18]$. Despite its high prevalence and importance, postnatal depression is commonly under-diagnosed by health professionals $[19,20]$.

The prevalence of postnatal depression in Bahrain is unknown and screening for known risk factors does not take place, even though the primary health care service provides postnatal checkups 6 weeks after delivery [21]. Despite the availability of the service, only $57 \%$ of Bahraini women comply with scheduled appointments [21]. On the other hand, women's compliance with the 8-week child vaccination schedule is high (93.6\%) [22]. The aim of this study was to provide data about the prevalence of postnatal depressive symptoms and associated risk factors among Bahraini women at 8 weeks postpartum.

\section{Methods}

This cross-sectional descriptive study was carried out on Arabic-speaking Bahraini women who were in the postnatal period, attending the 8-week child screening clinic at primary health care centres.

\section{Sample}

Using a confidence interval of $95 \%$ (a precision of 5\%) and an estimated prevalence of $20 \%$ [11,12], the sample size was calculated to be 250 .

The study participants were drawn from all 5 governorates of Bahrain through 20 randomly chosen primary health care centres and 2 clinics. A proportional sample was calculated for each governorate, health centre and clinic using the list of birth notifications relevant to each selected health centre that were collected over a period of 1 month from 15 May 2008 to 15 June 2008. The names of participant mothers were chosen by simple random sampling from those lists.

\section{Data collection}

Data collection was completed during the months of July and August 2008. Three instruments were used in the collection of data:

A birth notification form is issued for each newborn in Bahrain. A copy of this form is given to the parents and another one is sent to their corresponding health centre. It is mandatory to have the birth notification form in order to obtain a birth certificate for the newborn, and therefore all parents have to visit the health centre for registration purposes, regardless of the place of antenatal care visits and the place of delivery (i.e. public or private hospital). Information collected from the birth notification form included mother's age, number of live children, history of dead children in the family, and baby's sex, type of delivery, single/multiple births and gestational age.
The Arabic version of the Edinburgh Postnatal Depression Scale (EPDS) was used to screen for postnatal depression symptoms. The EPDS is a 10 -item self-report scale, specifically designed to screen for postnatal depression in community samples. The scale rates the intensity of depressive symptoms present within the previous 7 days [23]. Each item is scored on a 4-point scale (from 0 to 3 reflecting increased severity of symptoms). The minimum and maximum total scores are 0 and 30 , respectively, in which 0 is least depressed and 30 is most depressed. The Arabic version of the EPDS has been demonstrated to be a reliable and valid screening tool [24]. Gubash et al. found that using a cut-off score of 12 , the sensitivity and the specificity of the scale were $73 \%$ and $93 \%$ respectively. However, using a cut-off score of 10 , the sensitivity of the scale rose to $91 \%$ without much decrease in its specificity (84\%) [24]. In this study, a cut-off score of $\geq 12$ was used so that comparisons could be made with other regional studies.

A self-administered questionnaire reflecting important demographic, maternal, infant, and psychosocial risk factors for postnatal depression was appended to the EPDS [9-18].

A pilot study of recent mothers was conducted to assess the reliability of the Arabic EPDS and the self-administered questionnaire, and the validity was tested by seeking feedback from field experts, e.g. family physicians, midwives, community health nurses and specialists in obstetrics and gynaecology and psychiatry. Appropriate modifications were made to the questionnaire. The internal consistency of the Arabic version of the EPDS was checked using the data from the pilot study. The calculated Cronbach alpha was 0.82 , indicating a high inter-item consistency.

The EPDS and self-administered questionnaires were distributed by the researcher and designated maternal and child health nurses in each selected health centre, and collected at the time of 
the mother's attendance. Non-attendee mothers were followed up after 1 week. Face-to-face interviews with mothers who were unable to read and write were carried out by the researcher.

The research proposal was approved by the research and ethics committees of the Arabian Gulf University and the Ministry of Health. Informed consent was obtained from study participants. The instruments were coded to protect confidentiality and data from birth notification forms was extracted by the researcher only. Arrangements were made for appropriate referral of women identified at risk for depression.

\section{Data analysis}

Data were coded, entered and analysed using SPSS, version 16.0. Descriptive statistics including mean and standard deviation (SD) were used to describe continuous variables, and frequencies were used to describe categorical variables. Chi-squared test of independence was used to test the association between the dependant variable postnatal depressive symptoms and each of the sociodemographic, maternal, infant, social support and psychiatric health conditions. Fisher exact test was used for counts $<5$. Odds ratios (OR) were calculated with the $95 \%$ confidence intervals (CI) to measure the risk of postnatal depressive symptoms in relation to the studied risk factors. Multiple logistic regression was used to identify the most important risk factors. The model was estimated using the backward conditional logistic regression. Adjusted OR were calculated for the significant predictors. $P$-values $<0.05$ were considered statistically significant.

\section{Results}

A total of 237 Bahraini mothers took part in the study, representing a response rate of $94.8 \%$. More than onethird (37.1\%) of the women had EPDS score $\geq 12$.

\section{Demographic factors}

In terms of demographic factors, no significant associations were found between EPDS score $\geq 12$ and mother's age or age at marriage, educational level and occupation of mother and father, the marital status of the mother or the presence of another wife (Table 1).

\section{Pregnancy and birth factors}

Furthermore, no statistically significant relationships were found between postnatal depressive symptoms and: sex of the last born baby, type of delivery (vaginal or caesarean section), product of the delivery (single, twins or more), prematurity, health condition of the baby, birth order (firstborn or not), history of sibling death, history of separation from the newborn baby and breastfeeding or problems with breastfeeding (Table 2).

No statistically significant relationship was apparent between EPDS score and planning of the last pregnancy, timing of the last pregnancy and use of contraception (Table 3).

\section{History of depression and perceived support}

Table 4 shows the association between postnatal depressive symptoms and the mother's satisfaction with support at home, previous history of depressive symptoms, depression during pregnancy and a previous history of depression diagnosed by a health professional either in herself or family member. Mothers who were less satisfied with the help provided at home were more likely to have depressive symptoms than those who were satisfied. Further, when mothers did not perceive their husbands as involved in the care of the newborn, there was a significant association with EPDS scores of $\geq 12(P=0.002)$. Mothers who reported a previous history of depressive symptoms were 6 times more likely to have EPDS scores of $\geq 12$ than those without such history $(P<0.001)$. Mothers who had been previously diagnosed by a health professional as suffering from depression were
7 times more likely to have an EPDS score of $\geq 12$ than those without this diagnosis $(P=0.006)$. A family history of depression was also found to be significantly associated with the presence of postnatal depressive symptoms and mothers who reported such a history were almost 3 times more likely to have postnatal depressive symptoms than those without $(P=0.038)$.

In multiple logistic regression analysis a history of depressive symptoms (OR 8.13, 95\% CI: 3.77-17.5) $(P<$ $0.001)$ and not perceiving the husband as supportive (OR 2.41, 95\% CI: 1.244.69) $(P=0.01)$ were the only statistically significant independent predictors of postnatal depression (Table 5).

\section{Discussion}

Comparisons with studies of postnatal depression in other Arab countries are difficult because of variability in the tools used (screening, standardized diagnostic tools), the point in time applied, different cut-off points of the same tool and cultural issues $[5,8]$. Notwithstanding these difficulties, the prevalence of depressive symptoms in this study was higher than in other regional studies, and leads to a concern that the prevalence of postnatal depression may be commensurately higher.

In a study of 95 women in a hospital in Dubai, United Arab Emirates, using the Present State Examination (PSE) assessment, a prevalence of $15.8 \%$ for postnatal depression was reported [15]. In Morocco, the prevalence of postnatal depression at 2 weeks post-delivery was $18.7 \%$, using the Mini International Neuropsychiatric Interview (MINI), and $20.1 \%$, using a cut-off score of 12 with the EPDS [13]. Chaaya et al. in Lebanon using an EPDS score of 12/13 at 4-5 months postpartum recorded a prevalence rate of $21 \%$ [11], although at 4 months depression may have resolved spontaneously. 


\begin{tabular}{|c|c|c|c|c|c|}
\hline \multirow[t]{2}{*}{ Variable } & \multirow[t]{2}{*}{ Total no. } & \multicolumn{2}{|c|}{$\mathrm{EPDS} \geq 12$} & \multirow[t]{2}{*}{ OR $(95 \% \mathrm{Cl})$} & \multirow[t]{2}{*}{$P$-value } \\
\hline & & No. & $\%$ & & \\
\hline Mother's age (years) & & & & & 0.572 \\
\hline $17-20$ & 8 & 4 & 50.0 & & \\
\hline $21-30$ & 127 & 49 & 38.6 & & \\
\hline $31-40$ & 92 & 33 & 35.9 & & \\
\hline $41-44$ & 10 & 2 & 20.0 & & \\
\hline Mother's education & & & & & 0.264 \\
\hline Illiterate or read and write & 11 & 6 & 54.5 & & \\
\hline Primary or intermediate & 24 & 11 & 45.8 & & \\
\hline Secondary or diploma & 114 & 36 & 31.6 & & \\
\hline University & 88 & 35 & 39.8 & & \\
\hline Mother's occupation & & & & & 0.311 \\
\hline Housewife & 145 & 49 & 33.8 & & \\
\hline Employed & 74 & 30 & 40.5 & & \\
\hline Student & 18 & 9 & 50.0 & & \\
\hline Age at marriage (years) & & & & & 0.570 \\
\hline $11-20$ & 91 & 36 & 39.6 & & \\
\hline $21-30$ & 138 & 48 & 34.8 & & \\
\hline $31-39$ & 8 & 4 & 50.0 & & \\
\hline Father's education & & & & & 0.502 \\
\hline Illiterate or read and write & 5 & 2 & 40.0 & & \\
\hline Primary or intermediate & 54 & 20 & 37.0 & & \\
\hline Secondary or diploma & 114 & 47 & 41.2 & & \\
\hline University & 64 & 19 & 29.7 & & \\
\hline Father's occupation & & & & $2.32(0.51-10.6)$ & $0.429^{a}$ \\
\hline Working & 230 & 84 & 36.5 & & \\
\hline Not working & 7 & 4 & 57.1 & & \\
\hline Marital profile & & & & $0.38(0.06-2.34)$ & $0.362^{\mathrm{a}}$ \\
\hline One wife & 230 & 84 & 36.5 & & \\
\hline More than one wife & 5 & 3 & 60.0 & & \\
\hline
\end{tabular}

The total of some variables vary due to missing values. ${ }^{a}$ Fisher exact test was used because some cells have expected count $<5$. $O R=$ odds ratio; $C I=$ confidence interval.

As for risk factors, the current study showed that a previous history of depressive symptoms reported by the mother was significantly associated with postnatal depression scores. This finding is in accordance with other studies. Indeed, a history of depression or depressive symptoms and of depression during pregnancy are among the most important and significant predictors of postnataldepression $[8,10,15,16,25,26]$.

Despite the fact that depression during pregnancy is a strong predictor of postnatal depression, the current study did not show any significant relationship between postnatal depression and depressive symptoms reported during pregnancy. This can be attributed first, to the small sample size of this study, and second, to the point in the postnatal period under evaluation, i.e. 8 weeks. O'Hara and Swain found in their metaanalysis that assessment at 1 or 2 weeks postnatal was strongly associated with pregnancy depression, while assessment at 9 weeks was only weakly associated with depression [8]. Of course, it is possible that an in-pregnancy depression had not resolved.

In contrast with other studies $[10,11,16,26]$, the logistic regression analysis in this study did not show a significant relationship between family history of depression and postnatal depressive symptoms, and this agrees with the meta-analysis of O'Hara and Swain [8]. The other risk factor identified in this study, as in others, concerned support for the new mother at home. Lack of support was shown in this study to be strongly correlated with depressive symptoms, and has been linked consistently with postnatal depression $[8,26]$.

Traditionally after the birth of a child in Bahrain, the mother moves to live with her own mother for 40 days before she returns back to her husband's house. During this time, the new mother is relieved from her normal duties, which are taken over by female relatives. 


\begin{tabular}{|c|c|c|c|c|c|}
\hline \multirow[t]{2}{*}{ Variable } & \multirow[t]{2}{*}{ Total no. } & \multicolumn{2}{|c|}{$E P D S \geq 12$} & \multirow[t]{2}{*}{ OR $(95 \% \mathrm{Cl})$} & \multirow[t]{2}{*}{$P$-value } \\
\hline & & No. & $\%$ & & \\
\hline Baby's sex & & & & $0.94(0.55-1.59)$ & 0.808 \\
\hline Male & 108 & 41 & 38.0 & & \\
\hline Female & 129 & 47 & 36.4 & & \\
\hline Type of delivery & & & & $1.57(0.85-2.90)$ & 0.145 \\
\hline Vaginal & 182 & 63 & 34.6 & & \\
\hline Caesarean & 55 & 25 & 45.5 & & \\
\hline Product of delivery & & & & $3.50(0.63-19.5)$ & $0.198^{\mathrm{a}}$ \\
\hline Singleton & 231 & 84 & 36.4 & & \\
\hline Twins or more & 6 & 4 & 66.7 & & \\
\hline Gestational age & & & & $1.19(0.46-2.65)$ & 0.835 \\
\hline Term & 214 & 79 & 36.9 & & \\
\hline Premature & 23 & 9 & 39.1 & & \\
\hline Birth order & & & & $0.99(0.57-1.71)$ & 0.959 \\
\hline First child & 83 & 31 & 37.4 & & \\
\hline Second or greater & 154 & 57 & 37.0 & & \\
\hline \multicolumn{6}{|l|}{ Baby was sick } \\
\hline Yes & 7 & 4 & 57.1 & $0.43(0.09-1.98)$ & $0.429^{\mathrm{a}}$ \\
\hline No & 230 & 84 & 36.5 & & \\
\hline \multicolumn{6}{|l|}{ Separated from baby } \\
\hline Yes & 36 & 18 & 50.0 & $0.54(0.26-1.09)$ & 0.084 \\
\hline No & 198 & 69 & 34.8 & & \\
\hline \multicolumn{6}{|c|}{ History of a dead sibling in the family } \\
\hline Yes & 13 & 5 & 38.5 & $1.06(0.34-3.35)$ & $1.000^{\mathrm{a}}$ \\
\hline No & 224 & 83 & 37.1 & & \\
\hline \multicolumn{6}{|l|}{ Breastfed } \\
\hline Yes & 230 & 85 & 37.0 & $1.08(0.34-8.64)$ & $0.674^{\mathrm{a}}$ \\
\hline No & 6 & 3 & 50.0 & & \\
\hline \multicolumn{6}{|c|}{ Problems with breastfeeding } \\
\hline Yes & 83 & 37 & 44.6 & $0.62(0.36-1.06)$ & 0.081 \\
\hline No & 154 & 51 & 33.1 & & \\
\hline
\end{tabular}

${ }^{a}$ Fisher exact test.

$O R=$ odds ratio; $C I=$ confidence interval.

\begin{tabular}{|c|c|c|c|c|c|}
\hline \multirow[t]{2}{*}{ Variable } & \multirow[t]{2}{*}{ Total no. } & \multicolumn{2}{|c|}{$E P D S \geq 12$} & \multirow[t]{2}{*}{ OR $(95 \% \mathrm{CI})$} & \multirow[t]{2}{*}{$P$-value } \\
\hline & & No. & $\%$ & & \\
\hline Marital status & & & & $1.70(0.11-27.5)$ & $1.000^{\mathrm{a}}$ \\
\hline Married & 235 & 87 & 37.0 & & \\
\hline Divorced & 2 & 1 & 50.0 & & \\
\hline \multicolumn{6}{|c|}{ Pregnancy was desired } \\
\hline Yes & 171 & 60 & 35.1 & $1.36(0.76-2.44)$ & 0.295 \\
\hline No & 66 & 28 & 42.4 & & \\
\hline \multicolumn{6}{|c|}{ Timing of last pregnancy was suitable } \\
\hline Yes & 152 & 54 & 35.5 & $1.21(0.70-2.09)$ & 0.494 \\
\hline No & 85 & 34 & 40.0 & & \\
\hline \multicolumn{6}{|c|}{ Got pregnant while using contraception } \\
\hline Yes & 45 & 15 & 33.3 & $1.24(0.62-2.46)$ & 0.542 \\
\hline No & 191 & 73 & 38.2 & & \\
\hline
\end{tabular}

${ }^{a}$ Fisher exact test.

$O R=$ odds ratio; $C I=$ confidence interval. 


\begin{tabular}{|c|c|c|c|c|c|}
\hline \multirow[t]{2}{*}{ Variable } & \multirow[t]{2}{*}{ Total no. } & \multicolumn{2}{|c|}{ EPDS score $\geq 12$} & \multirow[t]{2}{*}{ OR $(95 \% \mathrm{Cl})$} & \multirow[t]{2}{*}{$P$-value } \\
\hline & & No. & $\%$ & & \\
\hline \multicolumn{6}{|c|}{ Satisfied with help at home } \\
\hline Yes & 192 & 66 & 34.4 & $2.00(1.03-3.90)$ & 0.04 \\
\hline No & 43 & 22 & 51.2 & & \\
\hline \multicolumn{6}{|c|}{ Help provided by husband } \\
\hline Yes & 130 & 37 & 28.5 & $2.33(1.36-4.00)$ & 0.002 \\
\hline No & 106 & 51 & 48.1 & & \\
\hline \multicolumn{6}{|c|}{ Help provided by mother } \\
\hline Yes & 107 & 36 & 33.6 & $1.33(0.78-2.27)$ & 0.292 \\
\hline No & 129 & 52 & 40.3 & & \\
\hline \multicolumn{6}{|c|}{ History of depressive symptoms } \\
\hline Yes & 64 & 44 & 68.8 & $6.45(3.44-12.05)$ & $<0.001$ \\
\hline No & 173 & 44 & 25.4 & & \\
\hline \multicolumn{6}{|c|}{ Previous diagnosis of depression } \\
\hline Yes & 10 & 8 & 80.0 & $7.35(1.52-35.7)$ & $0.006^{\mathrm{a}}$ \\
\hline No & 227 & 80 & 35.2 & & \\
\hline \multicolumn{6}{|c|}{ Diagnosis of depression during pregnancy } \\
\hline Yes & 1 & 1 & 100.0 & $2.71(2.30-3.21)$ & $0.371^{\mathrm{a}}$ \\
\hline No & 236 & 87 & 36.9 & & \\
\hline \multicolumn{6}{|c|}{ Family history of depression } \\
\hline Yes & 18 & 11 & 61.1 & $2.77(1.03-7.46)$ & 0.038 \\
\hline No & 188 & 68 & 36.2 & & \\
\hline
\end{tabular}

${ }^{a}$ Fisher exact test.

$O R=$ odds ratio; $C I=$ confidence interval.

This extended family system is a potent source of support in the Bahraini community and it is a duty of its members to support each other as far as they are able. This traditional custom is becoming less common these days, however. A study in the UAE found that more than half of the new mothers returned to their homes and only about onethird went to their mother's home [12]. Bahrain may be in a transitional stage, but this issue was not explored in this study.

In the current research, the support offered by participants' mothers and husbands, was examined. No significant association with EPDS score $\geq 12$ was found when the participant's mother was not identified as a provider of support. On the other hand, when the husband was not identified as a support, this was found on logistic regression to be a risk factor. Whether this perception was a reflection of reality or a manifestation of depressive symptoms could not be determined in this study. Two further studies have examined the importance of social support, and in particular partner support, as risk factors for postnatal depression $[27,28]$ and confirm this study's finding.

In conclusion, this study showed a high rate of depressive symptoms among Bahraini mothers at 8 weeks postpartum, with a previous history of depressive symptoms and the husband's perceived lack of social support emerging as associated risk factors. As the prevalence of symptoms was high in comparison with other studies conducted in the region, this study's findings need to be corroborated by a similar study that is supplemented by the inclusion of an appropriate diagnostic tool. If such research were to confirm a higher level of depression than might be expected, then the implications for the health care system are important. Considerable effort and resources would be needed to mount both prevention and treatment programmes.

Table 5 Multiple logistic regression analysis of the risk factors for a high score on the Edinburgh Postnatal Depression Scale $(\geq 12)$

\begin{tabular}{lcc} 
Risk factor & OR (95\% Cl) & $P$-value \\
Husband not perceived as supportive & $2.41(1.24-4.69)$ & 0.01 \\
History of depressive symptoms & $8.13(3.77-17.5)$ & $<0.001$ \\
\hline
\end{tabular}

$O R=$ odds ratio; $\mathrm{Cl}=$ confidence interval. 


\section{Acknowledgements}

We would like to thank the women who participated in this study for their cooperation. We would also like to thank Mr Mohammed Obaidat, lecturer at the Arabian Gulf University, for his assistance in the statistical part of the study.
This work was derived from a thesis submitted in partial fulfilment of the Master's degree in Health Policy and Population Studies, Arabian Gulf University.

\section{References}

1. Moehler E et al. Maternal depressive symptoms in postnatal period are associated with long term impairment of motherchild bounding. Archive of Women's Mental Health, 2006, 9 (5):273-278.

2. Murray L. The impact of postnatal depression on infant development. Journal of Child Psychology and Psychiatry, and Allied Disciplines, 1992, 33:543-561.

3. Cogill SR et al. Impact of maternal postnatal depression on cognitive development of young children. British Medical Journal, 1986, 292:1165-1167.

4. Patel V, Rodrigues M, De Souza N. Postnatal depression and infant growth and development in low income countries: a cohort study from Goa, India. Archives of Disease in Childhood, 2003, 88:34-37.

5. Rahman A et al. Impact of maternal depression on infant nutritional status and illness. A cohort study. Archives of General Psychiatry, 2004, 61:946-952.

6. Helbreich U, Karkun S. Cross-cultural and social diversity of prevalence of postpartum depression and depressive symptoms. Journal of Affective Disorders, 2006, 91:97-111.

7. Josefsson A et al. Prevalence of depressive symptoms in late pregnancy and postpartum. Acta Obstetricia et Gynecologica Scandinavica, 2001, 80:251-255.

8. O'Hara MW, Swain AM. Rates and risk of postpartum depression: a meta-analysis. International Review of Psychiatry, 1996, 8:37-54.

9. Husain $\mathrm{N}$ et al. Prevalence and social correlates of postnatal depression in a low income country. Archives of Women's Mental Health, 2006, 9:197-202.

10. Inandi T et al. Risk factors for depression in postnatal first year in eastern Turkey. International Journal of Epidemiology, 2002, 31:1201-1207.

11. Chaaya $\mathrm{M}$ et al. Postpartum depression: prevalence and determinants in Lebanon. Archives of Women's Mental Health, 2002, 5(2):65-72.

12. Green K, Broome H, Mirabella J. Postnatal depression among mothers in the United Arab Emirates: socio-cultural and physical factors. Psychology Health and Medicine, 2006, 11:425-431.

13. Agoub M, Moussaoui D, Battas O. Prevalence of postpartum depression in Moroccan sample. Archives of Women's Mental Health, 2005, 8(1):37-43.

14. Patel V, Rodrigues M, De Souza N. Gender, poverty and postnatal depression: a study of mothers in Goa, India. American Journal of Psychiatry, 2002, 159:43-47.

15. Ghubash R, Abou-Saleh MT. Postpartum psychiatric illness in Arab culture: prevalence and psychosocial correlates. British Journal of Psychiatry, 1997, 171:65-68.
16. Steiner M. Postnatal depression: a few simple questions. Family Practice, 2002, 19:469-470.

17. Chandran $\mathrm{M}$ et al. Post-partum depression in a cohort of women from a rural area of Tamil Nadu, India. Incidence and risk factors. British Journal of Psychiatry, 2002, 181:499-504.

18. Iranfar $\mathrm{S}$ et al. Is unintended pregnancy a risk factor for depression in Iranian women? Eastern Mediterranean Health Journal, 2005, 11:618-624.

19. Evins GG, Theofrastous JP, Galvin SL. Postpartum depression: a comparison of screening and routine clinical evaluation. American Journal of Obstetrics and Gynecology, 2000, 182(5):1080-1082.

20. Seehusen DA et al. Are family physicians appropriately screening for postpartum depression? Journal of the American Board of Family Practice, 2005, 18:104-112.

21. Al Kawari MA. A survey among Bahraini women on the utilization of postnatal check-ups: policy implications [Master's thesis]. Manama, Bahrain, Department of Family Medicine, Arabian Gulf University, 2007:101.

22. Health statistics 2008. Health Information Directorate, Ministry of Health, Bahrain [online database] (http://www.moh.gov. bh/PDF/Publications/Statistics/HS2008/hs2008_e.htm, accessed 1 March 2012).

23. Dennis CL. Detection, prevention and treatment of postpartum depression. In: Stewart DE et al., eds. Postpartum depression: literature review of risk factors and interventions. Toronto, Faculty of Nursing, University of Toronto, University Health Network Women's Health Program, 2003:73-196.

24. Ghubash R, Abu-Saleh MT, Daradkah TK. The validity of the Arabic Edinburgh postnatal depression scale. Social Psychiatry and Psychiatric Epidemiology, 1997, 32:474-476.

25. Dennis C-L, Ross LE. The clinical utility of maternal self-report personal and familial psychiatric history in identifying women at risk for postpartum depression. Acta Obstetricia et Gynecologica Scandinavica, 2006, 85:1179-1185.

26. Verkerk GJM et al. Prediction of depression in the postpartum period: a longitudinal follow-up study in high-risk and low-risk women. Journal of Affective Disorders, 2003, 77:159-166.

27. Dennis C-L, Janssen PA, Singer J. Identifying women at-risk for postpartum depression in the immediate postpartum period. Acta Psychiatrica Scandinavica, 2004, 110:338-346.

28. Dennis C-L, Ross L. Women's perceptions of partner support and conflict in the development of postpartum depressive symptoms. Journal of Advanced Nursing, 2006, 56:588-599. 